\title{
Dois críticos, uma semana, um século
}

[ Two critics, one week, one century

\section{Francisco Alambert ${ }^{\mathrm{I}}$}

\section{Tiago Ferro ${ }^{2}$}

RESUMO - Não é comum, em lugar algum, que dois críticos literários surjam entre os melhores explicadores de uma nação por quase um século. Partindo da análise schwarziana do método crítico de Antonio Candido, o ensaio explora as relações de afinidade e de diferenciação dos dois críticos literários confrontados em dois momentos decisivos: o modernismo e o legado de 1930 e o desenvolvimentismo (e seu fracasso) desde o Golpe de I964. PALAVRAS-CHAVE • Roberto Schwarz; Antonio Candido; intérpretes do Brasil. · ABSTRACT - It is not ordinary anywhere that two literary critics emerge among the best explainers of a nation for nearly a century. Starting from the schwarzian analysis of Antonio Candido's critical method, the essay explores the affinity and differentiation relations of both critics confronted at two turning points: modernism and the legacy of I930, and developmentalism (and its failure) since the coup d'état of 1964. - KEYWORDS - Roberto Schwarz; Antonio Candido; Brazil's explainers.

Recebido em 28 de março de 2019

Aprovado em 23 de outubro de 2019

ALAMBERT, Francisco; FERRO, Tiago. Dois críticos, uma semana, um século. Revista do Instituto de Estudos Brasileiros, Brasil, n. 74, p. I62-I77, dez. 2019.

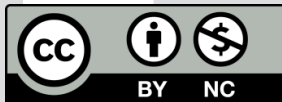

DOI: http://dx.doi.org/10.11606/issn.2316-901X.v0i74p162-177

\footnotetext{
I Universidade de São Paulo (USP, São Paulo, SP, Brasil).

2 Universidade de São Paulo (USP, São Paulo, SP, Brasil).
} 
A teoria dialética - caso não queira cair em mero economicismo e numa mentalidade segundo a qual a modificação do mundo se esgote em aumentar a produção - está obrigada a assumir para si a crítica de cultura [...]. Se a teoria dialética se mostra desinteressada pela cultura enquanto um mero epifenômeno, então ela contribui para que o desconcerto cultural continue a se propagar e colaborar na reprodução do que é ruim (Adorno, I982, p. 85).

“Só em I970 [...] é que seria publicado no Brasil o primeiro estudo literário propriamente dialético”, firmou Roberto Schwarz (2006a, p. I29) a respeito de "Dialética da malandragem", de Antonio Candido. A citação está no ensaio "Pressupostos, salvo engano, de 'Dialética da malandragem”" (I979), que nos guiará nesta tentativa, também ela algo ensaística, de situar certas especificidades dos lugares históricos dos dois críticos para além da mera "continuidade" entre mestre e discípulo, professor e aluno3.

As afinidades entre mestre e discípulo costumam constar na maioria das análises da trajetória do segundo. E o próprio Schwarz nunca deixou de confirmá-las, tanto em artigos como em entrevistas. Seguindo essas pistas, é possível afirmar que dois momentos da produção de Antonio Candido são particularmente importantes para Schwarz: o livro Formação da literatura brasileira e o ensaio "Dialética da malandragem". O primeiro, por sua investigação das formas de adaptação da cultura universal em ambiente local, abrindo caminho para especulações sobre o comportamento de culturas em situação pós-colonial; o segundo, pela aplicação

3 Por "ensaio" entendemos, com Adorno: “O ensaio não quer captar o eterno nem destilá-lo do transitório; prefere perenizar o transitório. A sua fraqueza testemunha a própria não identidade, que ele deve expressar; testemunha o excesso da intenção sobre a coisa e, com isso, aquela utopia excluída na divisão do mundo entre o eterno e o perecível. Naquilo que é enfaticamente ensaio, o pensamento se libera da ideia tradicional de verdade. Com isso ele suspende ao mesmo tempo o conceito tradicional de método. [...] [O ensaio] não começa com Adão e Eva, mas com aquilo que quer falar; diz o que lhe ocorre, termina onde ele mesmo acha que acabou e não onde nada mais resta a dizer" (ADORNO, I986, p. I75, I68). 
prática da dialética entre forma literária e processo social, ideia-chave da melhor produção schwarziana. Na apresentação da coletânea Antonio Candido Ioo anos, de 20I8, Schwarz menciona o livro e o ensaio, e também "Literatura e subdesenvolvimento" e "De cortiço a cortiço" (SCHWARZ, 20I8, p. I2-I3). Reflexões sobre o trabalho de Antonio Candido aparecem em diversos momentos da produção de seu ex-aluno, com destaque para os quatro textos que abrem o livro Sequências brasileiras (SCHWARZ, I999).

Se a geração de Roberto Schwarz buscou mergulhar em Marx (cf. RODRIGUES, 20II) e na necessidade de adaptá-lo para a realidade terceiro-mundista com o intuito de encontrar as mediações pelas quais a ordem mundial molda as realidades periféricas do capitalismo, o crítico, em entrevista de 2009 para o livro comemorativo de 40 anos do Centro Brasileiro de Análise e Planejamento (Cebrap), deixa claro que Antonio Candido, no campo estético (e sem se preocupar com filiações teóricas rígidas), estava lado a lado com as mesmas questões. Sobre uma suposta quebra geracional, Schwarz afirma:

A geração é anterior, a referência teórica é outra, mas o momento é o mesmo. Em “Dialética da malandragem”, por exemplo, você tem a descrição de uma especificidade brasileira que é confrontada, sem preconceitos, a uma forma canônica de literatura ocidental, sendo que a discrepância ajuda a interrogar o presente do país e do mundo. Quer dizer, é a mesma preocupação de colocar as peculiaridades nacionais na atualidade do mundo e de fazer que um âmbito se espelhe no outro a bem da reflexão. O Antonio Candido não faz isso a partir de um esquema marxista - e isso mostra que talvez o esquema marxista não fosse tão importante -, mas as preocupações eram comuns a todos. (SCHWARZ, 2009, p. 233).

As declarações reiteradas de Schwarz sobre sua relação intelectual com Antonio Candido evidenciam o esforço do único crítico literário do grupo do "Seminário Marx" de se situar na linhagem dos primeiros "críticos puros" do país: os do Grupo Clima, constituído, segundo o próprio Antonio Candido, por "Críticos, críticos e mais críticos" (CANDIDO, Antonio apud PONTES, I998, p. I3). Cabe acrescentar que tal esforço recebia acolhida de Antonio Candido ao eleger o seu grupo de influência (comparando com o grupo que orbitava Florestan Fernandes na antiga Faculdade de Filosofia, Ciências e Letras da Universidade de São Paulo - FFCL/USP): "[Roberto Schwarz, Walnice Nogueira Galvão, Davi Arrigucci Jr., João Lafetá, José Miguel Wisnik] esses são os meus Fernando Henriques, os meus Otávio Iannis” (entrevista de Antonio Candido a Mariza Peirano apud RODRIGUES, 20II, p. I6).

Por seu turno, o discípulo mais proeminente do “Seminário", Fernando Henrique Cardoso, incorporou, segundo seus interesses de intérprete e problematizador da teoria do desenvolvimento cepalina, sua ligação com o duo Candido-Schwarz:

Entre os críticos da cultura na América Latina existe um debate intermitente, mas não desinteressante, a respeito dos efeitos da dependência sobre a produção das ideias. Alguns dos mais argutos teóricos da literatura brasileira (como Antonio Candido de Mello e Souza e Roberto Schwarz) vêm procurando mostrar que a mesma ideia, uma vez transferida dos centros de produção internacional de cultura para a periferia, vira outra coisa. (CARDOSO, I980, p. I7). 
Após trazer para o mesmo campo de problemática a pioneira análise de João Cruz Costa sobre o transplante do positivismo no Brasil, o sociólogo retoma a polêmica ainda muito quente das "ideias fora do lugar", diante da qual seu livro de ensaios também pretende se posicionar. Cardoso apreende a análise de Schwarz (entendida como parte e continuidade do trabalho de Antonio Candido) como uma espécie de teoria do "consumo das ideias importadas", usando para explicá-la uma metáfora biológica: "Uma espécie de ecologia cultural interessada nos efeitos dos transplantes de hábitat sobre as delicadas hastes da ideologia” (CARDOSO, I980, p. I8)4.

Como veremos, as afinidades e desejos de reconhecimento mútuo entre os dois críticos estudados neste ensaio, sempre buscando em alguma medida controlar a recepção futura da própria obra, acabam por se embaralhar quando nos aproximamos da história e do arriscado jogo de estabelecimento de grupos pelos agentes interessados.

O ensaio de Antonio Candido sobre Memórias de um sargento de milícias realiza o projeto dialético da forma artística e do processo social que orientará as pesquisas de Schwarz sobre Machado de Assis, e também ilumina suas preocupações em relação ao realismo literário. Apesar de pobre quanto às descrições das especificidades do local histórico no qual se passa a trama das Memórias, o romance ainda assim cria um sentido forte de realismo. Acompanhando e desvendando o método de Antonio Candido, Schwarz explica como se dá o processo:

Usando as expressões de Antonio Candido, esta forma é tanto um esqueleto de sustentação do romance, quanto a redução estrutural de um dado social externo à literatura e pertencente à história. Trata-se, noutras palavras, da formalização estética de um ritmo geral da sociedade brasileira da primeira metade do século XIX. (SCHWARZ, I987a, p. I32).

E ainda: “[...] a dialética de ordem e desordem é um princípio de generalização que organiza em profundidade tanto os dados da realidade quanto os da ficção (sejam ou não documentários), dando-lhes inteligibilidade" (SCHWARZ, I987a, p. I33)5.

O que está em jogo no ensaio de Antonio Candido é a descoberta, na forma literária, de um dado organizador do processo social que, por sua vez, é também formal. Ou seja: a dialética da ordem e desordem é um achado duplo, e não apenas o encontro na obra artística de algo já conhecido da vida em sociedade.

As implicações da descoberta são profundas. Em recente trabalho, Nicholas

4 Lidiane S. Rodrigues (20II, p. 5I7) entende que Fernando H. Cardoso "a rigor, defende seu ex-aluno, não a interpretação dele, posto que do approach que compartilharam anteriormente, o sociólogo já se enfastiou e se distanciou".

5 O próprio Antonio Candido refletiu longamente sobre seu "método" e as relações entre literatura e processo social em Literatura e sociedade (20I7). 
Brown, pesquisador marxista norte-americano estudioso da obra de Schwarz, se debruça sobre o assunto:

By "emancipated" form, Schwarz means that in a successful work the link between literary and social form is not itself a directly social process. It neither takes place through the development of preexisting generic forms (which, in relation to self-legislating form, are merely raw material), nor through a "political unconscious" that insists behind the back of the novelist. [...] The creation of literary form is a cognitive act, even though, as we shall see, it is a cognitive act of a peculiar sort. Before it was intuited and made objective by the novelist, the form that the critic studies was produced by the social process, even if nobody was aware of it. (BROWN, 20I8, p. 466)

Portanto, o realismo intuído nas Memórias tem a ver com certa forma social pertencente ao real, mas que não é um fato evidente do texto (e nem da sociedade). A soma de acontecimentos, como já havia mostrado a Nova História (cf. NOVAIS; SILVA, 2OII), não cria sentido ou amplia a inteligibilidade de um período histórico. É preciso encontrar as linhas de força subterrâneas. E essa procura representará boa parte do projeto das humanidades durante o século XX. No plano do pensamento franco-europeu, de Braudel a Lévi-Strauss, todos procuram o que não pode ser visto a olho nu7 . Mais adiante, o devir deleuziano e os mecanismos de poder descritos por Foucault também legariam o que está dado na realidade ao segundo plano. Aqui é possível começar a compreender a complexidade do que foi realizado por Antonio Candido e sua importância em âmbito mundial. E também por Schwarz em seus estudos sobre Machado de Assis, principalmente nos dois livros: Ao vencedor as batatas (I977) e Um mestre na periferia do capitalismo (I990).

Em "Pressupostos”, Schwarz disseca ponto por ponto o método de Antonio Candido. Não cabe acompanhar todo o processo neste breve ensaio. No entanto, a operação sugere a construção de seu próprio lugar intelectual, o encaixe das peças de um espelho no qual as pesquisas do discípulo estariam refletidas na obra do mestre que deixou para as próximas gerações diversas vias abertas.

Com o resumo feito até aqui, parece evidente e localizada a dívida metodológica (dialética) entre aluno e professor. Entretanto, avançando nos "Pressupostos", vamos

6 Em tradução livre: "Por forma 'emancipada', Schwarz afirma que, em um trabalho bem-sucedido, o vínculo entre forma literária e sociedade não é em si um processo diretamente social. Não se dá através do desenvolvimento de formas genéricas preexistentes (as quais, em relação à forma autolegislativa, são apenas matéria-prima), nem através de um 'inconsciente político' que insista por trás do romancista. [...] A criação da forma literária é um ato cognitivo, contudo, como veremos, é um ato cognitivo de tipo peculiar. Antes de ser intuída e objetivada pelo romancista, a forma que a crítica estuda foi produzida pelo processo social, mesmo que ninguém tivesse consciência disso". A referência ao "inconsciente político" remete ao conceito operacionalizado por Fredric Jameson para analisar, à sua maneira (quer dizer, distante da problemática das peculiaridades da condição moderna na periferia do capitalismo), a relação entre mimese e realidade na narrativa literária entendida como uma prática coletiva que sedimenta no texto "soluções imaginárias ou formais para contradições insolúveis" (JAMESON, I992, p. 72).

7 Já nos anos 1930, o olhar culturalista antropológico de Franz Boas compreendia que, quando se olha para algo, o que se vê é o efeito da tradição: “o olho que vê é órgão da tradição” (apud BOAS, I987). 
encontrar nas páginas finais pontos de deslocamento entre ambos que, acreditamos, repousam não na análise das Memórias, mas em outro momento da cultura brasileira. Schwarz inicia a virada do ensaio assim: "é certo que em "Dialética da malandragem" a forma literária recebe um tratamento mais estruturado que a realidade social. Esta diferença não aparece na exposição que fizemos, pois procuramos salientar o jogo entre as estruturas literária e histórica" (SCHWARZ, I987a, p. I49).

Ao não marcar no plano da história os limites precisos da dialética da ordem e desordem, Antonio Candido teria sugerido uma constante cultural que o aproximaria de intérpretes modernistas da história do Brasil - como Sérgio Buarque de Holanda e Gilberto Freyre - e suas tentativas de identificação de certo "caráter nacional”. Ou seja, ao generalizar um suposto modo de ser do brasileiro, partindo de características de uma classe social específica e a dissolvendo para todas as demais, sem exemplos concretos do funcionamento do mecanismo na história, a dialética da ordem e desordem corria o risco de operar como ideologia. Isto pelo fato de Antonio Candido ter dado (ainda segundo Schwarz) muita atenção para o funcionamento da forma no objeto estético e pouca especificidade dessa forma na estrutura social. Uma "ideologia" muito especial, uma vez que tinha em sua origem não a visão de mundo produzida pelas elites (que Antonio Candido aprendeu com Sérgio Buarque), mas, inversamente, a da "sociabilidade desenvolvida pelos homens pobres" (SCHWARZ, I987a, p. I50).

Schwarz (I987a, p. I5I) prossegue investigando o que caracterizaria como a "originalidade ideológica" do ensaio. Para o crítico, ao abrir mão de investigar historicamente a descoberta feita entre padrão universal e ambiente local da composição estética do romance, Antonio Candido teria interrompido o processo dialético, tomando partido da visão de mundo do livro. O "mundo sem culpa" criado pela dialética da ordem e desordem ganha sinal positivo no ensaio e valor a-histórico como possibilidade de desenvolvimento para o país.

A "dialética da malandragem", da maneira como é conceituada/descoberta nas Memórias, segundo Antonio Candido (20I0c, p. 46), "facilitará a nossa inserção num mundo eventualmente aberto". Ou seja, e resumindo: superado o capitalismo, algo profundamente brasileiro - cômico, irreverente, amoral - deixa de ser desvantagem e passa a nos colocar com menos dramas de consciência nesse mundo mais aberto. Ressalte-se que Antonio Candido (20I7c, p. 46) sugere rapidamente uma genealogia estética dessa ideia que "se manifesta em Pedro Malasarte no nível folclórico e encontra em Gregório de Matos expressões rutilantes, que reaparecem de modo periódico, até alcançar no Modernismo as suas expressões máximas, com Macunaíma e Serafim Ponte Grande". Guardemos essa referência aos modernistas de 22.

Roberto Schwarz expõe o que há de ideológico no argumento apontando o que ocorre quando o processo dialético é congelado e transportado no tempo:

[...] a repressão desencadeada a partir de I969-com seus interesses clandestinos em faixa própria, sem definição de responsabilidades, e sempre a bem daquela mesma modernidade - não participava ela também da dialética de ordem e desordem? É talvez um argumento indicando que só no plano dos traços culturais malandragem e capitalismo se opõem... (SCHWARZ, I987a, p. I54). 
A malandragem, nem precisaria ser repetido, era "coisa nossa" e estava figurada na cultura em uma larga tipologia (do "vagabundo" ao "revolucionário"). Entre a publicação de "Dialética da malandragem" e "Pressupostos", Chico Buarque (artista que se tornaria cada vez mais importante para as reflexões de Roberto Schwarz, tanto como compositor de canções quanto como romancista) lançaria sua Ópera do malandro (I977). A canção "Homenagem ao malandro" também iria captar de modo flagrante o casamento feliz entre malandragem e capitalismo, ou seja, a realização do "mundo sem culpa do capital". Aqui, o que sugere deboche e ironia toma pé da realidade sem qualquer tipo de deslocamento. Em um país sempre em formação, a aproximação abusada de termos geralmente distantes tende a criar um senso de realismo forte ${ }^{8}$. Diz o trecho da letra:
Agora já não é normal
O que dá de malandro regular, profissional
Malandro com aparato de malandro oficial
Malandro candidato a malandro federal
Malandro com retrato na coluna social
Malandro com contrato, com gravata e capital
Que nunca se dá mal.
(grifos nossos).

Outro discípulo de Candido, José Miguel Wisnik, entra no debate com um precioso insight em livro de 2008:

Ao roubar a cena da "dialética da malandragem" que enformou a imagem do Brasil na primeira metade do século [XX] por meio do samba e do futebol, a dialética dura da marginalidade, sem síntese, sem folga e, afinal, sem dialética, marca a atmosfera geral do país com a lembrança surda e recalcada de um custo social não redimido. (WISNIK, 2008, p. 42I).

Schwarz encerra o ensaio novamente valorizando o tamanho do feito operado por Antonio Candido em "Dialética da malandragem", classificando-a como "a melhor peça da crítica dialética brasileira” (SCHWARZ, I987a, p. I54). Assim, não resta dúvida da importância do que foi realizado em termos teórico-metodológicos para futuras pesquisas de crítica materialista. Quanto ao problema ideológico levantado por Schwarz, cabe uma ressalva: a aposta de Antonio Candido no traço descoberto nas Memórias como vantagem para o país dependeria de um devir socialista, o que o afastaria de intérpretes que condicionaram o presente a partir de investigações

8 A questão está aprofundada na comparação entre Schwarz e Fredric Jameson feita por: Larsen, 2007. 
culturais e históricas do caráter nacional brasileiro (por exemplo, a já muito discutida e criticada, mas ainda viva e operando ideologicamente, "democracia racial" de Freyre)'.

Certos traços valorizados no trabalho crítico de Antonio Candido podem ser espelhados de forma sumária em alguns "compromissos" dos modernistas oriundos da Semana de Arte Moderna de I922 - o que obviamente está longe de esgotar as diversas influências decisivas do crítico, principalmente a formação em ciências sociais na USP. Arriscamos dizer que tais compromissos (ou acordos) seriam os seguintes: linguagem direta e clara, valorizando a importância da comunicação; uso livre (o que não significa sem critério) das referências estrangeiras; investigação do "ser" do Brasil num mesmo movimento que procura inseri-lo no andamento do mundo, do qual seríamos parte integrante (e ativa). E, claro, uma preponderante visão de mundo humorística, sempre tão bem lembrada por aqueles que conviveram com Antonio Candido e em saborosos textos como o manifesto "O grouchismo" (CANDIDO, 2009). Salvo engano, a aposta de Antonio Candido no "mundo sem culpa" descoberto nas Memórias como projeto de país deita raízes nas obras dos modernistas Mário de Andrade e Oswald de Andrade, como citado anteriormente. Principalmente na deste último. Como se sabe, de Oswald a Caetano, Schwarz vai dedicar boa parte de seu trabalho a apontar as ambiguidades e os limites ideológicos do projeto modernista, sem jamais desqualificar o nível estético e as profundas reflexões sobre o Brasil alcançados por boa parte dessa produção.

É possível encontrar, de forma indireta, esse ponto de desencontro entre Roberto Schwarz e Antonio Candido nas análises que os dois realizaram sobre Oswald de Andrade.

Em “Digressão sentimental de Oswald de Andrade", de I970, Antonio Candido revê suas posições do artigo "Estouro e libertação" publicado no livro Brigada ligeira, de I945, numa tentativa de dar conta de toda a obra do modernista. Em ambos os ensaios o crítico lança mão de dados biográficos para analisar os diversos livros e as fases nas quais classifica a produção oswaldiana. Apenas para efeito de contraste, em I945 Antonio Candido escreveu:

Seu [de Oswald] entusiasmo iconoclasta valeu como poucos para desabafar a literatura brasileira de uma série de anteparos e ilusões; sua crítica irreverente foi arma fecunda de derrubada; como agitador sua importância foi primordial.

Mas a obra, todavia, não correspondia exatamente à fama. (CANDIDO, 20I7a, p. 22).

9 Cf. dois estudos centrais, no debate da época, sobre ideologia, cultura e caráter nacional: Mota, 2008; Leite, 20I7. Sobre o primeiro, Antonio Candido o definiu como uma obra modelar do estilo do "pensar contra": “E este livro é muito mais da geração dos senhores alunos do que de nós, velhos professores; é um livro muito curioso, muito vivo, onde eu vejo uma proposição extremamente fecunda para a tendência desmistificadora que é a base do contra, quer dizer, não aceitar as coisas como elas aparecem e questionar incessantemente” (CANDIDO, 2002, p. 379). Evidentemente, Candido colocava Schwarz dentro da mesma linhagem “do contra”. 
Já no texto de I970 está selada na análise a aproximação entre crítico e autor. Lembrando que Antonio Candido foi amigo, compadre e testamenteiro de Oswald, o que não implica perda de juízo crítico. A biografia do escritor aparece então repleta de passagens bem-humoradas e tiradas de gênio, as quais Antonio Candido vivenciou diretamente ou por meio de colegas de geração. Uma certa história oral (ou memorabilia) entra em cena no ensaio. Vale destacar a emoção do episódio em que Oswald toma conhecimento da morte de Mário de Andrade, durante uma viagem de trem. O sentimento por Oswald está aberto e a serviço da crítica. Diferentemente de I945, agora, biografia e obra ganham melhor encaixe: "De um homem assim, pode-se dizer que a existência é tão importante quanto a obra” (CANDIDO, 20I7d, p. 77).

$\mathrm{O}$ estilo dos melhores romances oswaldianos - segundo Antonio Candido Memórias sentimentais de João Miramar e Serafim Ponte Grande - estaria afinado à personalidade do "homem". As dúvidas sobre o acerto de Marco Zero são justificadas também acionando o criador: "o mal de Oswald foi ter forçado a sua natureza artística, sacrificando a composição sincopada em benefício das sequências coesas" (CANDIDO, 20I7d, p. 8I). E ainda: "o Oswald divinatório enfraquece em proveito de um Oswald mais disciplinado e cinzento, corroído pelo 'realismo social' pouco ajustado às suas melhores tendências" (CANDIDO, 20I7d, p. 83). Observar o crítico rever suas posições e valorizar a empatia como método analítico, sem com isso perder o rigor com o objeto estético, criando uma nova forma de crítica com forte valor literário, estabelece novas sugestões para futuros pesquisadores.

É cabível argumentar que a adesão de Antonio Candido ao lado espirituoso do projeto modernista teria um corte geracional. Como vimos, em sua análise da obra oswaldiana, o uso de dados biográficos e a sua proximidade do objeto analisado reafirmam essa ideia, que só pode ser compreendida quando, passado o tempo, cristaliza-se um perfil geracional. Também quanto a Roberto Schwarz, certo "perfil", de caráter "biográfico", também pode ser colocado em cena como hipótese do jogo de afinidades e afastamentos entre os dois críticos que remonta ao modernismo de 22.

Roberto Schwarz, nascido em I938 na Áustria, chegou com um ano ao Brasil. Seus pais, judeus e militantes de esquerda, fugiram das perseguições nazistas em I939, que logo resultariam na Segunda Guerra Mundial. O fato biográfico é relevante, uma vez que nosso autor cresceu no Brasil envolto por um ambiente cultural europeu traumatizado com os horrores do Velho Mundo em pleno século XX. É o próprio Schwarz quem fala sobre o local de seu círculo familiar de imigrantes: "Também o dono da casa era judeu alemão, e combinava o piano com a representação de uma firma de relógios. Digo isso para indicar que era um ambiente de imigrantes, em que o progresso no domínio do português, bem como o acesso à intelectualidade brasileira, eram problema" (SCHWARZ apud MICELI, 2007, p. 6I).

Sobre o trecho citado, Sergio Miceli afirma que:

Essas características de sua peculiar inserção na sociedade brasileira - como a experiência de sentir-se prensado entre o alemão e o português, entre dois universos culturais de expressão e pensamento - me parecem bem mais esclarecedoras do feitio assumido por seu projeto intelectual do que a toada de filiações teóricas e sintonias militantes. (MICELI, 2007, p. 6I). 
Antes de seguirmos para a maneira como Antonio Candido fala desse lugar schwarziano destacado por Miceli, cabe um passo atrás.

A situação de origem particular de sua Áustria natal pode ter tido consequências para a percepção dialética do futuro crítico. Alguns historiadores demonstraram que a Áustria fin-de-siècle representava uma situação muito particular dentro do contexto europeu $^{\mathrm{Io}}$. O decadente Império Austro-húngaro, na virada do século XIX para o século XX, era de fato um polo fraco no continente modernizado. Ali, a burguesia liberal fora incapaz de se impor diante de uma aristocracia moribunda, neuroticamente presa ao drama de sua crescente dependência e inferioridade diante da Alemanha unificada que era, para a maioria dos intelectuais e artistas vienenses, o modelo (ou não) de sua “identidade". Como resumiu Jacques Le Rider (I993, p. 29), tudo isso traduzia “a dificuldade de ser um inovador, um 'moderno' num meio cultural reputadamente conservador e hostil às menores audácias". Último bastião da cultura da fantasia aristocrática - onde, segundo Schöenberg, bailava-se "a dança fúnebre dos princípios" (apud SHORSKE, I989, p. I5) -, berço de Hitler e do antissemitismo como política de Estado, Viena foi também o palco no qual algumas das mais eminentes vanguardas artísticas e intelectuais (Freud, Wittgenstein, Escola de Viena, o expressionismo, o austro-marxismo) armaram alguns dos princípios de resistência culturais e políticos mais notáveis e influentes do século XX. A contradição animava particularmente o processo, e a agitação intelectual não escapava ao olhar perspicaz de Robert Musil, que escreveu sobre aquele momento:

Quem não viveu naquela época vai achar difícil acreditar, mas o fato é que, mesmo então, o tempo estava passando mais rápido do que um camelo de montaria. [...] Mas, naqueles dias, ninguém sabia para onde ele andava. Nem ninguém conseguia distinguir entre o que estava em cima e o que estava embaixo, entre o que estava indo para a frente e o que ia para trás. (MUSIL apud SCHORSKE, I989, p. I25).

O berço cultural de Schwarz é portanto esse império sacudindo simultaneamente dentro e fora da Europa moderna. Uma espécie de ponto de partida bastante significativo para quem iria se dedicar a entender os ajustes ideológicos e culturais de uma sociedade particularmente atrasada e inserida desde o início no concerto capitalista. Um lugar onde também os princípios bailavam e o meio cultural hegemônico era "conservador e hostil às menores audácias".

Em 2004, Antonio Candido abriu o seminário na Universidade de São Paulo dedicado à obra de seu ex-aluno. $\mathrm{O}$ discurso se transformou no "Sobre Roberto Schwarz". Candido reconhecia ali o valor do discípulo: "Roberto Schwarz, amigo que estimo e colega que admiro como um dos críticos mais bem-dotados e mais originais que a literatura brasileira já teve" (CANDIDO, 2007a, p. I3). Em alguns apontamentos rápidos e precisos, o mestre salienta o dado biográfico: "Eu diria que Roberto construiu lentamente um estilo crítico revelador das suas posições, a partir

Io Dentre os vários livros sobre a vida cultural vienense do princípio do século XX, destaque-se o belo estudo de Carl Schorske, I989. Ver também o estudo mais aprofundado sobre a influência da cultura austríaca na formação de Roberto Schwarz em: Alambert, I998. 
de um olhar duplo, de dentro e de fora. E mais: que este duplo olhar talvez esteja ligado à sua história pessoal de brasileiro que é ao mesmo tempo de fora e de dentro" (CANDIDO, 2007a, p. I5).

Adiante, Antonio Candido tratará da situação do crítico em países periféricos de forma geral, que, diferentemente do crítico europeu, que pode se bastar nas referências de sua própria cultura, tem que ser sempre ele mesmo e um outro. Assim, a perspectiva de dentro e de fora, segundo Antonio Candido, estaria na própria constituição, como experiência formativa, de Schwarz: "isso lhe permite ver o Brasil como quem é de dentro e de fora por natureza, o que produz uma combinação sui generis de estranhamento e familiaridade, a qual deve ter contribuído para o cunho singular da sua lucidez analítica" (CANDIDO, 2007a, p. I6) ${ }^{\text {II }}$.

Em "A carroça, o bonde e o poeta modernista", de I983, Roberto Schwarz (I987) buscou expor o que haveria de ideologicamente problemático na obra de Oswald. É nos temas mobilizados no poema "pobre alimária" que o crítico encontra a contradição e a ambiguidade de um projeto modernizador que segue preso a aspectos arcaicos da sociedade brasileira. A indústria que surgia e prometia nos inserir no mundo de forma inédita mantinha lastro nas relações de trabalho com ares de escravidão da cafeicultura. $\mathrm{O}$ atrasado convivendo com o progresso como dado empírico da realidade brasileira daria o tempero realista ao projeto modernista que não cumpriria o mesmo papel que na Europa. O universo colonial insistia em dar as caras em meio às operações formais modernas. E era, de diferentes maneiras, figurado em suas esquisitices.

Paulo Arantes, em livro que tem como figuras centrais justamente Candido e Schwarz, tratando do ensaio de I983 do segundo, sintetiza assim a descoberta crítica: "Roberto se encarregará de mostrar que é ao modernismo que devemos a transformação da convivência entre primitivismo e modernidade em álibi de classe" (ARANTES, I992, p. IOI).

Em síntese, no ensaio em questão, o crítico analisa a configuração de "mundo sem culpa" encontrada no poema "pobre alimária”, de Oswald. Schwarz escreve:

Pessoas, bichos, coisas e lugares, além de se oporem, suspiram em uníssono por uma forma de vida superior, um lugar menos atrasado, onde carroças fossem veículos, motorneiros fossem autoridades e advogados não sofressem contratempos. Contudo, pelo paradoxo central à poesia pau-brasil, o desterro será o paraíso. (SCHWARZ, I987, p. I6).

Se Oswald insere nosso atraso no mundo com ar de piada, Caetano Veloso, que no mesmo ensaio é citado indiretamente por Schwarz (1987, p. I3) - "Ainda há pouco o Tropicalismo lhe [o poema 'pau-brasil'] deu a versão correspondente ao pós-64” -,

II É Ereciso lembrar, mais uma vez, que esse "olhar" a que o crítico se refere (bem como outros comentadores) não é exatamente aquele apreendido, em tradição familiar, na cultura "avançada” da Europa liberal e moderna. Antes o contrário: "sempre causou grande surpresa o contraste existente entre um estilo de governo neoabsolutista carregado de sobrevivências arcaicas e uma sociedade largamente modernizada” (LE RIDER, I993, p. 37). 
no andamento eufórico da canção “Tropicália”, recoloca a questão: "Viva a bossa, sa, sa/ Viva a palhoça, ça, ça, ça, ça”². Celebra-se assim (ou não?) o que há de mais odioso no passado brasileiro que nunca passa, a vida miserável na palhoça que convive lado a lado na letra da canção (e na realidade) com outro grande feito de nossa cultura, a bossa nova, ela também herdeira da solução modernista.

No poema oswaldiano, Schwarz (I987, p. 26) nota que o desfecho que resolve a confusão do animal empacado sobre o trilho do bonde que transporta os advogados atrasados significa "a intervenção do chicote que restabelece a ordem". Chicote que vai passar de uma geração a outra em Leite derramado, romance de Chico Buarque, identificando o mando e a violência como baixo-contínuo de nossa história, apesar de tantos avanços ${ }^{\mathrm{I3}}$.

No belo ensaio "O ato crítico", de I978, Antonio Candido fala da influência de Sérgio Milliet sobre ele e o grupo de intelectuais ao qual pertencia. Ao chamar Milliet de "homem-ponte", estabelece um corte e ao mesmo tempo cria um grupo geracional para seu pertencimento: "nós estávamos na casa dos vinte e ele na dos quarenta” (CANDIDO, 20I7e, p. I48). (Aliás, coincidência boa, o mesmo intervalo entre Candido e Schwarz.) Ao longo do ensaio o crítico distingue encontros e desencontros teóricos e políticos para costurar, consciente das dificuldades e perigos do estabelecimento rígido de influências, ("terreno falível e perigoso das influências”), o lugar de sua própria geração. Nesse jogo especular, encerra o ensaio com Milliet resumindo Gide, que para Candido "se ajusta perfeitamente a ele [Sérgio Milliet] próprio”. Assim, o caminho das influências e construções de locais intelectuais e cristalizações geracionais pode seguir indefinidamente para o passado nesse tipo de genealogia intelectual.

Mas avancemos: após o caminho percorrido neste ensaio, seria possível classificar Antonio Candido como "homem-ponte" para a geração de Roberto Schwarz, que em grande medida é definida pelo projeto do grupo do "Seminário Marx". Se Candido permitiu as aventuras dialéticas de Schwarz em uma cultura periférica que ele tão bem reconheceu, este, a partir daí, trilhou caminho próprio, com as preocupações e ferramentas de seu tempo (além das que ele mesmo foi criando). Não seria portanto nem arbitrário nem obtuso sintetizar a fórmula: Antonio Candido teria sido um

I2 No mais recente livro de Roberto Schwarz, é justamente o ensaio sobre Caetano Veloso, analisado a partir da autobiografia do músico, que gerou mais debate e repercussão. Consolida-se assim a importância do artista tropicalista para as reflexões do crítico, que têm início com o ensaio de I970 "Cultura e política (I964-I969)" (cf. VELOSO, 2008; SCHWARZ, 20I2a; 2008a).

I3 Ao tratar dessas persistências históricas arcaicas a partir da leitura de Leite derramado (BUARQUE, 2009), Schwarz capta o efeito deletério desse traço da nossa "modernização conservadora": "É como se o presente continuasse a informalidade do passado patriarcal, multiplicando-a por mil, dando-lhe a escala das massas, para melhor ou para pior. Talvez seja isso o leite derramado que não adianta chorar: persistiu a desigualdade, desapareceram o decoro e a autoridade encasacada, e não se instalaram o direito e a lei” (SCHWARZ, 2OI2, p. I50). 
dos grandes intérpretes do Brasil no contexto da revolução de I930 até o Golpe Civil-Militar de I964; Roberto Schwarz também o foi, sobretudo a partir do contexto do Golpe. Se a formulação parece simplista, fiquemos então com um espanto que deriva dela: não é comum, em lugar algum, que dois críticos literários surjam entre os melhores explicadores de uma nação por quase um século.

Roberto Schwarz foi um duplo exilado. Cruzou o Atlântico recém-nascido com sua família fugindo da perseguição nazista aos judeus (que em sua cidade natal já era um fato político real desde antes do fim do século XIX) e depois voltou para a Europa por conta da perseguição às esquerdas no Brasil da ditadura civil-militar. Gestado na Europa e publicado pela primeira vez em francês em I972, seu ensaio mais famoso - "As ideias fora do lugar" - foi sua principal elaboração crítica da "ideologia brasileira”, uma espécie de método para análise de objetos estéticos na periferia do capitalismo, fundamento teórico da análise cerrada da primeira fase do romance machadiano, revelando o ritmo da realidade brasileira que permitiria que o gênio da segunda fase irrompesse. $O$ projeto schwarziano em grande medida acompanharia como as torções, distorções e contradições dessa "esquisitice brasileira" enformariam nosso campo estético e cultural para nos trazer entendimentos históricos e sociais fundamentais do Brasil pós-I964. Mesmo quando o descompasso entre ideias e chão histórico permitiu nossas melhores realizações estéticas, o crítico nunca aderiu a elas como projeto para o país. Com tantos deslocamentos em sua biografia, e sempre pensando em como as ideias operam travessias e se acomodam em realidades estrangeiras periféricas e pós-coloniais, para Roberto Schwarz, a história (sempre) foi a prova dos nove.

\section{SOBRE OS AUTORES}

FRANCISCO ALAMBERT é professor do Departamento de História da Faculdade de Filosofia, Letras e Ciências Humanas da Universidade de São Paulo (FFLCH/USP). E-mail: alambert@usp.br https://orcid.org/0000-0003-3167-369X

TIAGO FERRO é doutorando do Programa de PósGraduação em História da FFLCH/USP. E-mail: tiago-ferro@uol.com.br https://orcid.org/oooo-0002-8574-3I66 


\section{REFERÊNCIAS}

ADORNO, Theodor. O ensaio como forma. In: COHN, G. (Org.). T. W. Adorno: sociologia. São Paulo: Ática, I986, p. I67-I87. (Grandes Cientistas Sociais).

. Notas de literatura I. São Paulo: Duas Cidades; Ed. 34, 2003.

. Teoria estética. Lisboa: Edições 70, 2008.

ALAMBERT, Francisco. Lugar da dialética, dialética do lugar: três notas sobre filiações, finalidades e afinidades na formação intelectual de Roberto Schwarz. In: LOUREIRO, Isabel; MUSSE, Ricardo (Org.). Capítulos do marxismo ocidental. São Paulo: Fundação Editora da Unesp/Fapesp, I998.

ALMEIDA, Manuel Antonio de. Memórias de um sargento de milícias. São Paulo: Globo, 2004.

ANDERSON, Perry. Considerações sobre o marxismo ocidental: nas trilhas do materialismo histórico. São Paulo: Boitempo, 2004.

ANDRADE, Oswald de. Pau Brasil. São Paulo: Globo, 2000.

ARANTES, Paulo Eduardo. Sentimento da dialética na experiência intelectual brasileira: dialética e dualidade segundo Antonio Candido e Roberto Schwarz. Rio de Janeiro: Paz e Terra, I992.

. Um departamento francês de Ultramar: estudos sobre a formação da cultura filosófica uspiana. Rio de Janeiro: Paz e Terra, I994.

BROWN, Nicholas. Roberto Schwarz: mimesis beyond realism. In: BEST, Beverley; BONEFELD, Werner; O'KANE, Chris (Ed.). The Sage Handbook of Frankfurt School Critical Theory. Sage Publications, 2018, p. $465-478$.

BOAS, F. Anthropology and modern life. Nova York: Dover Publications, I987.

BUARQUE, Chico. Leite derramado. São Paulo: Companhia das Letras, 2009.

BUARQUE DE HOLANDA, Sérgio. Raízes do Brasil. São Paulo: Companhia das Letras, 2016.

CANDIDO, Antonio. O tempo do contra. In: Textos de intervenção/Antonio Candido. Seleção, apresentações e notas de Vinícius Dantas. São Paulo: Duas Cidades/Editora 34, 2002, p. 369-380. (Coleção Espírito Crítico).

. Formação da literatura brasileira. São Paulo: Ouro Sobre Azul, 2007.

. Sobre Roberto Schwarz. In: CEVASCO, Maria Elisa; OHATA, Milton (Org.). Um crítico na periferia do capitalismo: reflexões sobre a obra de Roberto Schwarz. São Paulo: Companhia das Letras, 2007a, p. I3-I7. . O grouchismo. Serrote, n. 2, São Paulo, IMS, 2009, p. I66-I69.

Brigada ligeira. São Paulo: Ouro Sobre Azul, 20I7a.

. Literatura e sociedade. São Paulo: Ouro Sobre Azul, 20I7b.

. O discurso e a cidade. São Paulo: Ouro Sobre Azul, 20I7c.

. Vários escritos. São Paulo: Ouro Sobre Azul, 20I7d.

. O ato crítico. In:__. . A educação pela noite. São Paulo: Ouro sobre azul, 2oI7e.

CARDOSO, Fernando Henrique. A originalidade da cópia: a CEPAL e a ideia de desenvolvimento. In:

As ideias e seu lugar: ensaios sobre as teorias do desenvolvimento. Petrópolis: Vozes, I980, p. I7-56.

. Capitalismo e escravidão no Brasil meridional. Rio de Janeiro: Paz e Terra, I997.

CEVASCO, Maria Elisa; OHATA, Milton (Org.). Um crítico na periferia do capitalismo: reflexões sobre a obra de Roberto Schwarz. São Paulo: Companhia das Letras, 2007.

DANTAS, V. (Org.). Textos de intervenção/Antonio Candido. São Paulo: Duas Cidades/Editora 34, 2002. (Coleção Espírito Crítico).

GLEDSON, John. Roberto Schwarz: Um mestre na periferia do capitalismo - um guia para leitores anglófonos. In: Por um novo Machado de Assis: ensaios. São Paulo: Companhia das Letras, 2006, p. 236-278. 
HOLANDA, Sérgio Buarque de. Raízes do Brasil. São Paulo: Companhia das Letras, 2015.

JAMESON, F. O inconsciente político: a narrativa como ato socialmente simbólico. São Paulo: Ática, I992. . A lógica cultural do capitalismo tardio. In: . Pós-modernismo: a lógica cultural do capitalismo tardio. São Paulo: Ática, I996.

LARSEN, Neil. Por que ninguém consegue entender Roberto Schwarz nos Estados Unidos?. In: CEVASCO, Maria Elisa; OHATA, Milton (Org.). Um crítico na periferia do capitalismo: reflexões sobre a obra de Roberto Schwarz. São Paulo: Companhia das Letras, 2007, p. I8-22.

LEITE, Dante Moreira. O caráter nacional brasileiro. São Paulo: Unesp, 2017.

LE RIDER, J. A modernidade vienense e as crises de identidade. Rio de Janeiro: Civilização Brasileira, I993. LUKÁCS, Georg. A teoria do romance. São Paulo: Editora 34, 2000.

. História e consciência de classe: estudos sobre a dialética marxista. São Paulo: Martins Fontes, 2003. MICELI, Sergio . O chão e as nuvens: ensaios de Roberto Schwarz entre arte e ciência. In: CEVASCO, Maria Elisa; OHATA, Milton (Org.). Um crítico na periferia do capitalismo: reflexões sobre a obra de Roberto Schwarz. São Paulo: Companhia das Letras, 2007.

MOTA, Carlos Guilherme. Vanguarda e conformismo, segundo Roberto Schwarz. In: . Ideologia da cultura brasileira (I933-I974). São Paulo: Ática, I994, p. 245-249. . Ideologia da cultura brasileira (I933-I974). São Paulo: Editora 34, 2008.

NOVAIS, Fernando Novais; SILVA, Rogerio F. (Org.). Nova história em perspectiva. v. I. São Paulo: Cosac Naify, 20II.

OLIVEIRA, Francisco de. Crítica à razão dualista/O ornitorrinco. São Paulo: Boitempo, 2003.

PONTES, Heloisa. Destinos mistos: os críticos do Grupo Clima em São Paulo (I940-I968). São Paulo: Companhia das Letras, I998.

RODRIGUES, Lidiane Soares. A produção social do marxismo universitário em São Paulo: mestres, discípulos e "um seminário" (I958-I978). Tese (Doutorado em História Social). Faculdade de Filosofia, Letras e Ciências Humanas, Universidade de São Paulo, 20 II.

SALES GOMES, Paulo Emílio. Cinema: trajetória no subdesenvolvimento. Rio de Janeiro: Paz e Terra, I996. SCHORSKE, Carl. Viena fin-de-siècle: política e cultura. São Paulo: Companhia das Letras, I989.

SCHWARZ, Roberto. Que horas são?: ensaios. São Paulo: Companhia das Letras, I987. . (I979). Pressupostos, salvo engano, de "Dialética da malandragem". In: Que horas são? : ensaios. São Paulo: Companhia das Letras, I987a, p. I29-I59.

. Duas meninas. São Paulo: Companhia das Letras, I997. . Sequências brasileiras: ensaios. São Paulo: Companhia das Letras, I999. . Um mestre na periferia do capitalismo. São Paulo: Editora 34, $2000 a$. . Ao vencedor as batatas. São Paulo: Editora 34, 2000 b. . O pai de família. São Paulo: Companhia das Letras, 2008. . Cultura e política (I964-I969). In: O pai de família. São Paulo: Companhia das Letras, 2008a. . Entrevista. In: MONTERO, Paula; Moura, Flávio (Org.). Retrato de grupo: 40 anos do Cebrap. São Paulo: Cosac Naify, 2009.

. Martinha versus Lucrécia. São Paulo: Companhia das Letras, 2012.

. Verdade tropical: um percurso de nosso tempo". In: . Martinha versus Lucrécia. São Paulo:

Companhia das Letras, 20I2a.

. Cetim laranja sobre fundo escuro. In: . Martinha versus Lucrécia. São Paulo: Companhia das

Letras, 20I2b.

. As ideias fora do lugar. São Paulo: Companhia das Letras, 20I4. . Antonio Candido I9I8-20I7. New Left Review, Londres, I07, set.-out. 2017. 
. Antonio Candido Ioo anos. In: FONSECA, Maria Augusta; SCHWARZ, Roberto (Org.). Antonio Candido Ioo anos. São Paulo: Editora 34, p. I2-I3.

VELOSO, Caetano. Verdade tropical. São Paulo: Companhia das Letras, 2008.

WISNIK, José Miguel. Veneno remédio. São Paulo: Companhia das Letras, 2008. 